\title{
Manometric and radiographic evaluation of transduodenal sphincteroplasty (papillary dilation) in dogs ${ }^{1}$
}

\author{
Avaliação manométrica e radiográfica da esfincteroplastia transduodenal \\ (dilatação papilar) em cães
}

\begin{abstract}
Martin Zavadinack Netto², Djalma José Fagundes ${ }^{3}$, César Orlando Peralta Bandeira²
1. Research from Post-graduation Program in Surgery and Experimentation of Federal University of São Paulo (UNIFESP), Brazil.

2. PhD in Basic Sciences in Surgery and Experimentation of UNIFESP and Associate Professor of Surgery Department of State University of Maringá, Paraná, Brazil.

3. Associate Professor of Surgery Department of UNIFESP and Coordinator of Post-graduation Program in Surgery and Experimentation of UNIFESP, Brazil.
\end{abstract}

\begin{abstract}
Purpose: To evaluate, in dogs, the functions of biliary sphincter subjected to dilation hydrostatic balloon by the point of view of the radiographic and manometric alterations. Methods: Twenty dogs were submitted to laparotomy, duodenotomy, and enlargement of the major duodenal papilla- $\mathrm{GA}(\mathrm{n}=10)$ - with balloon of $8 \mathrm{~mm}$ inflated with pressure of 0 ,5atm, during 2 minutes or to the sham procedure - $\mathrm{GB}(\mathrm{n}=10)$. The computadorized manometry and the cholangiography were done before and immediately after the initial procedure, one and four weeks after the dilation or the sham. It was calculated from the radiographic images: the mean, standard deviation, absolute and percentual variation of the diameter measures of the papilla. It was measured: the basal pressure in the papilla region, the contraction amplitudes and the choledoc pressure in all observation times ( $\mathrm{t} 0, \mathrm{t} 7$ and $\mathrm{t} 28$ ). Results: There was not differences in the diameter measures of the papilla in $\mathrm{t} 0$ $(\mathrm{GA}=5,14+/-1,1)(\mathrm{GB}=4,64+/-0,9)$, as well as in the absolute $(0,14 \mathrm{~mm})$ or relative $(-2,7 \%)$ variations. In the animals of $\mathrm{GA}$ the papilla basal pressure measure was found to be smaller in $\mathrm{t} 28(11,1)$ than in t0 $(18,6)$ and $t 7(16,2)$. The contraction amplitudes measures were significantly smaller in the postoperatory times (post-t0, $\mathrm{t} 7$ and $\mathrm{t} 28$ ) when comparing to the initial time (pre-t0), in the animals of groups A and B. The average pressure values in the choledoc were also smaller in t28 $(7,5)$ than in $t 0(17,8)$ and $t 7(12,6)$ in the animals of GA. Conclusion: the function of the major duodenal papilla is partially commited with the dilation, therefore it provoked the basal pressure decrease and compromising of the capacity of sphincter in its cyclical contractions up to the 28 days of observation.
\end{abstract}

Key words: Sphincterotomy, Transhepatic. Balloon Dilatation. Sphincter of Oddi. Cholangiography.

\section{RESUMO}

Objetivo: Avaliar, em cães, a função da papila duodenal maior submetidas à dilatação por balão hidrostático sob o ponto de vista das alterações radiográficas e manométricas. Métodos: Vinte cães foram submetidos a laparotomia, duodenotomia, dilatação da papila maior - GA(n=10) - com balão de $8 \mathrm{~mm}$ insuflado com pressão de 0,5atm, durante 2 minutos ou ao procedimento simulado - $\mathrm{GB}(\mathrm{n}=10)$. A manometria computadorizada e a colangiografia foram efetuadas antes e imediatamente após o procedimento inicial, uma e quatro semanas após a dilatação ou a simulação. Foram calculadas à partir das imagens radiográficas: a média, desvio-padrão, mediana, variação absoluta e porcentual das medidas do diâmetro da papila. Foram medidas: a pressão basal na região da papila, a amplitude das contrações e a pressão do colédoco em todos tempos de observação(t0, t7 e t28). Resultados: Não houve diferença nas medidas do diâmetro da papila em t0 (GA=5,14 e DP=1,1) $(\mathrm{GB}=4,64$ e $\mathrm{DP}=0,9)$, assim como nas variações absolutas $(0,14 \mathrm{~mm})$ ou relativas $(-2,7 \%)$. Nos animais do GA a medida da pressão basal da papila, mostrou-se menor no t28 $(11,1)$ que nos tempos t0 $(18,6)$ e T7 $(16,2)$. As médias das amplitudes de contração foram significantemente inferiores nos tempos pós-operatórios (pós-t0, t7 e t28) em relação ao tempo inicial (pré-t0), nos animais dos grupos A e B. Os valores médios da pressão no colédoco também foram inferiores em t28 (7,5) que nos tempos t0 $(17,8)$ e t7 $(12,6)$ nos animais do GA. Conclusão: A função da papila duodenal está comprometida parcialmente com a dilatação, pois provocou diminuição da pressão basal e comprometimento da capacidade do esfíncter em suas contrações cíclicas até aos 28 dias de observação.

Descritores: Esfincteroplastia Transhepática. Dilatação com Balão. Esfíncter da Ampola Hepatopancreática. Colangiografia. 


\section{Introduction}

The endoscopic papillotomy is considered efficacious for the treatment of the lithiasis of the biliar ducts ${ }^{1,2}$, however the loss of function of the papilla, evidenced by the lack of pressure between the choledoc and the duodenum ${ }^{3}$, allows the duodenum-biliary reflux ${ }^{4}$.

The concept of minimally invasive intervention brought the expansion of the application of papillotomy to patients without high surgical risk and even as an intervention prior to cholecystectomy ${ }^{5}$. This broadening in indication should be analysed considering the evidences of the high risk of late complications, being a reason to worry, especially on what concerns the treatment of young patients, exposed for a long time to duodenum-biliary reflux, causing the search for alternatives ${ }^{6}$.

The endoscopic dilation of the major duodenal papillawith balloon was proposed as an option to papillotomy for the removal of stones from the biliary ducts ${ }^{7}$, proving to be as efficacious as papillotomy $y^{8,9,10}$, with the advantage of a smaller loss of functional capacity through the smaller reduction of the basal pressure of the sphincter. This eventual advantage of dilation on the basal pressure of the sphincter is not well characterized in experimental or clinical studies.

The purpose of this research was to verify the manometric and radiographic aspects that are part of the transduodenal sphincteroplasty with balloon, in a experimental animal model.

\section{Methods}

The experimental protocol was approved by the Ethics Comittee in animal experimentation of the Federal University of São Paulo - Escola Paulista de Medicina (UNIFESP-EPM), ratified and developed in the Central Bioterium of the Maringá State University (UEM). All the procedures followed, rigorously, the existent regulations about animal experimentation.

Twenty adult male dogs, average weigth of $12,5 \mathrm{Kg}$, with state of health comproved by veterinaries from the UEM Bioterium, were kept in ambient and diet proper for the species and under controlled ambient. The group A $(n=10)$ was submitted to a operatory procedure of dilation of the major duodenal papillawith use of hydrostatic balloon and the group $B(n=10)$ was submitted to the sham operatory procedure without the dilation.

\section{Anesthesia}

All the procedures were done under general anaesthesia, with spontaneous ventilation, using xylasine $2 \%$ (3mg/Kg), sodium thiopental 2,5\% (4mg/Kg) and infusion of sodium chloride $0,9 \%(20 \mathrm{ml} / \mathrm{Kg})$ in a superficial vein of the anterior member.

\section{Operatory procedures}

In conditions of asepsy and antisepsy it was done a medium laparotomy. The major duodenal papilla was found after longitudinal opening of the descending part of duodenum and subjected to manometry followed by papilla dilation (group A) or the sham procedure (group B) in time zero (t0). After seven (t7) and twenty-eight days (t28) the animals were subjected to new intervention for the procedures of manometry and cholangiography.

\section{Manometry}

The duodenal papilla was submitted to the passage od a catheter with external diameter of $1,7 \mathrm{~mm}$ and three canals, one for the passage of a guide wire and two for infusion of liquids. Each canal, for instillation, ended in lateral orifices with diameter of $0,5 \mathrm{~mm}$, distant $1,5 \mathrm{~cm}$ and $1,9 \mathrm{~cm}$ from the extremity. The two canals were perfunded with distilled water with pressure of $250 \mathrm{mmHg}$ in capilary flux of $0,33 \mathrm{ml} / \mathrm{min}$. The pressure oscilations were amplified by a polygrapher connected to a computer, with a graphic real time recording and archiving of information for posterior analysis. The catheter occlusion produced a pressure registry higher than $250 \mathrm{mmHg}$ and the system was able to register more than 40 pressure oscilations each minute. The perfusion orifices of the catheter were initially positioned in the level of the opening of the papilla so to establish the base line for all the pressure variations to be registered. Under direct vision, the major duodenal papilla was permeated by the catheter, which was positioned in the choledoc duct, remaining in this position for registry during three minutes, defining the choledoc duct pressure in the last minute of observation. The progressive removal of the catheter allowed the identification of a region with bigger pressure, in which was investigated the position that presented the cyclical contractions with bigger values. This position was considered to be the best representation of the contractive activity of the sphincter (Figure 1). The catheter was kept in position for the registry of the activity during five minutes, allowing the evaluation of basal pressure of the contraction amplitude. For the calculation of the basal pressure, it was used the average of pressure between the cyclical contractions, during the last minute of evaluation; and, for the calculation of the contraction amplitude, it was used the average of the cyclical contractions in the last minute of evaluation, minus the basal pressure.

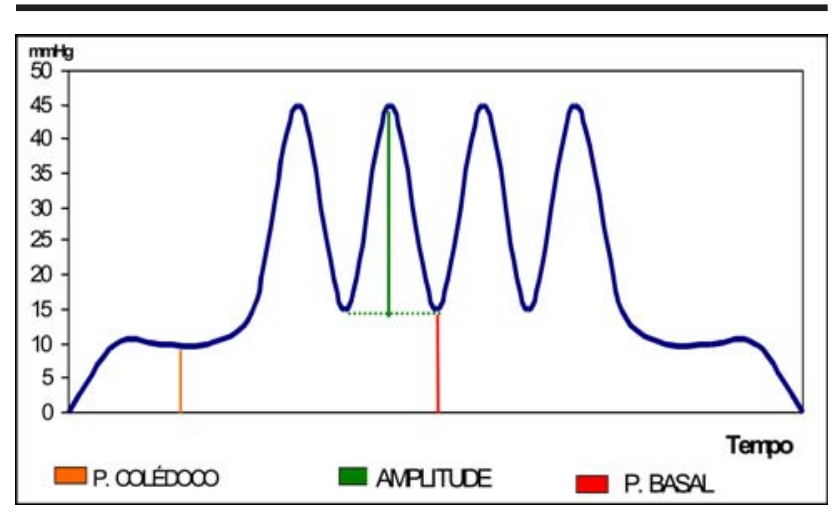

FIGURE 1 - Graphic representation of the considered parameters in the evaluation of contraction waves obtained through manomentry and registered in the computer 


\section{Cholangiography}

After the manometry, the cholangiography was done with instillation of iodinated contrast $60 \%$, through the guide wire canal of the manometry catheter, whose orifice was located in the choledoc duct. The radiography was executed woth $20 \mathrm{~mA}$ and $60 \mathrm{KV}$, using as standard the distance of 15 $\mathrm{cm}$ between the collimator and the choledoc duct. The evaluation of the diameter of the choledoc duct was done with the transverse measure of the image of the biliary duct, $1 \mathrm{~cm}$ above the constriction image of the major duodenal papilla (Figure 2).

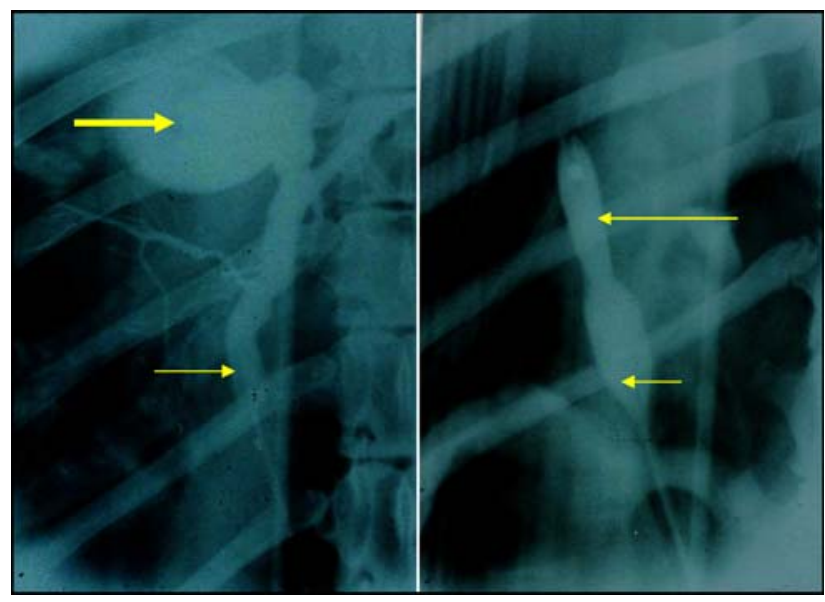

FIGURE 2 - To the right, radiologic image of vesicle (thick arrow) and extrahepaitc biliary ducts (thin arrow) representating an animal of group A before the dilation. To the left, radiologic image of the dilation balloon inflated in the choledoc duct (long arrow), papilla (arrow head) and duodenum (short arrow) of an animal of group $\mathrm{A}$.

\section{Papilla dilation}

Once the manometry catheter was removed, the 10 animals of group A were subjected to dilation of the major duodenal papilla. A guide wire was introducted in the biliary duct through the papilla, allowing the passage of a catheter with external diameter of $2,3 \mathrm{~mm}$ and a balloon with extention of $3 \mathrm{~cm}$; the balloon can reach an diameter of $8 \mathrm{~mm}$ when totally inflated. An iodenated contrast solution in $30 \%$ was injected to inflate the balloon during 30 seconds, until it was reached the pressure of $380 \mathrm{mmHg}$, which was kept during two minutes and afterwards the contrast was removed in 30 seconds. In the last minute of the inflation it was performed the radiography to evaluate the distention level of the balloon in the papilla region.

\section{Sham dilation procedure}

The major duodenal papilla and the choledoc duct of the 10 animals of group B (control) were permeated by the non-inflated catheter balloon, which remained in the choledoc duct during three minutes to simulate the dilation.
Once the catheter was removed, these animals were, just like the ones in group A (dilation), immediately evaluated as to measure basal pressure, contraction amplitude and choledoc duct pressure.

\section{Statistic study}

The statistic study was performed at the Biostatistic Discipline of the Department of Preventive Medicine of UNIFESP-EPM. According to the nature of the variables it was used non-parametric tests (Wilcoxon, Friedman, MannWhitney). The rejection level for the nullity hypothesis was set at 0.05 or $5 \%(p \leq 0,05)$, and the significant values were marked with an asterisk.

\section{Results}

TABLE 1 - Standard deviation average and median of the diameter measures ( $\mathrm{mm}$ ) of the radiologic image of choledoc duct in the animals of group A (with papilla dilation) and group B (sham), in the start of the procedures ( $\mathrm{t} 0$ )

\begin{tabular}{lll}
\hline Animals & GroupA & Group B \\
\hline Average & 5,14 & 4,64 \\
S.D. & 1,1 & 0,9 \\
Median & 4,8 & 4,4 \\
\hline
\end{tabular}

" $\mathrm{T}$ " test for independent groups (critical t 2,10) (calculated $\mathrm{t}=1,09$ ) No significant differences between the groups.

TABLE 2 - Average of measures (mm), absolute difference (mm) and percentual variation (\%) of radiologic images of choledoc duct and dilation balloon in the location of major duodenal papilla in the animals of group A (with papilla dilation)

\begin{tabular}{lcccc}
\hline Animals & $\begin{array}{c}\text { Choledoc } \\
\text { duct }\end{array}$ & Papilla & Diference & Variation \\
\hline Média & $\mathbf{5 , 1}$ & $\mathbf{5 , 0}$ & $\mathbf{- 0 , 1 4}$ & $\mathbf{- 2 , 7 \%}$ \\
\hline Wilcoxon test $\left(\mathrm{t}_{\text {calculated }}=17,5 \mathrm{t}_{\text {critical }}=5,0\right)$ & \\
No significant differences between the groups.
\end{tabular}

TABLE 3 - Animals of group A (with papilla dilation) and group B (sham), according to the values of average basal pressure (mmHg), evaluated before (pre t0) and immediately after (post t0) the dilation or sham of first procedure and in the complementary procedures (t7 and t28)

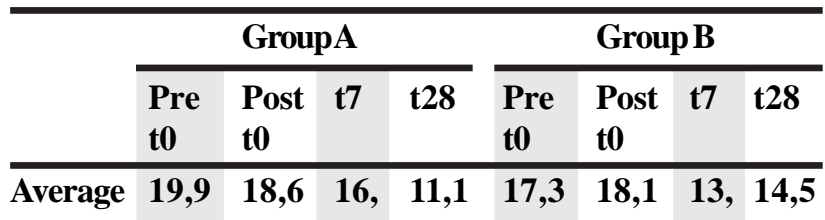

Variance analysis by Friedman's two-ways analysis

(Pre t0 x Post t0 x t7 x t28) $\chi_{\text {crít }}^{2}=7,82$

Group A $\chi_{\text {calc }}^{2}=8,52 *(\mathrm{t} 28<$ Pre t0 e Post $\mathrm{t} 0)$

Group $\chi_{\text {calc }}^{2}=5,67$

The basal pressure kept similar values in all animals of group A, except in the t28 moment when it became significantly smaller than in initial times Pre $\mathrm{t} 0$ and Post $\mathrm{t} 0$. In the animals of group $\mathrm{B}$ there were not significant differences. 
Mann-Whitney Test (Group A x Group B ) $U_{\text {crit }}=23$

Pre t0 $\mathrm{U}_{\text {calc }}=38,5$

Post t0 U $=41,0$

$\mathrm{t} 7 \mathrm{U}=41,0$

t28 $\mathrm{U}_{\text {calc }}^{\text {calc }}=22,5 *$ Group A $>$ B

The basal pressure in the two groups considering the different times showed there was no significant difference, except in t28 when the basal pressure was bigger in the animals of group A comparing with group $\mathrm{B}$.

TABLE 4 - Animals of group A (with papilla dilation) and group B (sham), according to the average values of contraction amplitude ( $\mathrm{mmHg}$ ), evaluated before (Pre t0) and immediately after (Post t0) the dilation or sham of first procedure and complementary procedures (t7 and t28)

\begin{tabular}{llllllllll}
\hline & GroupA & & & Group B & \\
\cline { 2 - 3 } \cline { 5 - 7 } & Pre & Post & t7 & t28 & & Pre & Post & t7 & t28 \\
t0 & t0 & & t0 & t0 & & \\
\hline
\end{tabular}

\begin{tabular}{lllllllll}
\hline Average & 39,8 & 25,1 & 22,6 & 26,8 & 29,6 & 32,2 & 16,8 & 20,9
\end{tabular}

Variance analysis by Friedman's two-ways analysis

(Pre t0 x Post t0 x t7 x t28) $\chi^{2}=7,82$

Group A $\chi_{\text {calc }}^{2}=8,52 *$

Group B $\chi_{\text {calc }}^{2}=12,72 *$

The averages of contraction amplitudes were significantly smaller in the postoperatory times (post $\mathrm{t} 0, \mathrm{t} 7$ and t28) comparing with the initial time $(\mathrm{t} 0)$ in the animals of group $\mathrm{A}$ and $\mathrm{B}$.

Mann - Whitney Test (Group A x Group B) $U_{\text {crít }}=23$

Pre t0 U $=32,0$

Post t0 U $U^{\text {calc }}=39,0$

t7 $\mathrm{U}=39,0$

t28 $\mathrm{U}_{\text {calc }}^{\text {calc }}=27,0$

The averages of contraction amplitudes were the same in the animals of groups $\mathrm{A}$ and $\mathrm{B}$, when paired up in the different operatory times (pre t0, post t0, t7 and t28).

TABLE 5 - Dogs from group A (with papila dilation) and group $\mathrm{B}$ (control), according to the values of choledoc duct pressure (mmHg) evaluated before (Pre t0) and immediately after (Post t0) the dilation and sham of the first procedure and in the complementary procedures ( $\mathrm{t} 7$ and $\mathrm{t} 28$ )

\begin{tabular}{|c|c|c|c|c|c|c|c|c|}
\hline & \multicolumn{4}{|c|}{ GroupA } & \multicolumn{4}{|c|}{ Group B } \\
\hline & $\begin{array}{l}\text { Pre } \\
\text { to }\end{array}$ & Post & $\mathbf{t 7}$ & t28 & $\begin{array}{l}\text { Pre } \\
\text { to }\end{array}$ & $\begin{array}{l}\text { Post } \\
\text { t0 }\end{array}$ & & t28 \\
\hline Average & 11,4 & 17,8 & 12,6 & 7,5 & 10,6 & 14,6 & 8,7 & 10,0 \\
\hline \multicolumn{9}{|c|}{$\begin{array}{l}\text { Variance analysis by Friedman's two-ways analysis } \\
(\text { Pre t0 } \mathrm{x} \text { Post } \mathrm{t} 0 \mathrm{xt} 7 \times \mathrm{t} 28) \chi_{\text {crit }}^{2}=7,82 \\
\text { Group } \mathrm{A} \chi_{\text {calc }}^{2}=14,82 * \mathrm{t} 28<\text { Pre t0, Post t0 e t7 } \\
\text { Group } \mathrm{B} \chi^{2} \text { calc }=6,0 \\
\text { Mann }- \text { Whitney Test (Group A x Group B) } \mathrm{U}_{\text {crit }}=23 \\
\text { Pre t0 } \mathrm{U}_{\text {calc }}=44,0 \\
\text { Post t0 } \mathrm{U}_{\text {calc }}=31,0 \\
\mathrm{t} 7 \mathrm{U}_{\text {calc }}=25,0 \\
\mathrm{t} 28 \mathrm{U}_{\text {calc }}=26,0\end{array}$} \\
\hline
\end{tabular}

\section{Discussion}

The dilation of the papilla with balloon for the removal of stones is referred to in the medical literature in at least a thousand cases $^{3,8,9,10,11,12,13}$. The anatomical and functional consequences, which only just recently started to receive attention, were not properly studied in experimental models. Hence the choice for the use of dogs, which present structure and function of the major duodenal papilla alike the humans, although it has choledoc and pancreatic ducts that drain through distinct orifices ${ }^{14}$.

The evaluation in the caliber of the choledoc duct, through cholangiography, showed homogeneity between the groups, for the median of the group of animals subjected to dilation was of $4,8 \mathrm{~mm}$, while the dilation of the control group was of 4,4 mm (Table 1). However, there was great variation in the caliber of the choledoc duct, from 3,2 $\mathrm{mm}$ to $7,2 \mathrm{~mm}$ between the animals; the variation was not related to the weigth of the animals. This variability, previously observed in the pilot study, was the reason that made impossible the dilation with a fixed value for all animals, for there would be different levels of dilation in each animal. On the other hand, the adoption of balloons with exact measures for each choledoc duct was also not possible, considering that the avaiable balloon measures are progressive each $2 \mathrm{~mm}$. The option to overcome this restrictions was the use of the method described by Pappas et $\mathrm{al}^{15}$, in which the pressure of dilation of papillas of animals of medium weight was defined, through trial and error, as 0,5 atm (380 mmHg). This pressure was described as one that can provoke the persistent relaxation of the papilla, allowing the migration of foreign bodies left in the gall bladder in equal quantities to what occurred when the papilotomy was performed; and bigger than in a group control, where the dilation was only simulated.

In spite of the information from the literature about the efficacy of this dilation method, it was considered important the confirmation of the level of dilation. Should it occur a resistence of the papilla to the balloon inflation, the preestablished pressure of 0,5 atm could not dilate it properly. The radiography of the dilation balloon, inflated with iodenated contrast, showed the papilla location as an annular constriction, with bigger proximal inflation for being in the duodenum, and distal for being in the choledoc duct, apparently more elastic than the papilla (Figure 2).

When the measure of the constriction location of the balloon (papilla region) was compared to the caliber of the choledoc before the dilation, it was observed values that were too close, with the papilla dilatation to bigger diameter than then the diameter of the choledoc duct in five animals, same diameter in two and smaller diameter in three animals. The diameter average of the balloon in the papilla region and the diameter of the choledoc duct did not present statistic difference, confirming the papilla dilation till a diameter closer to the one of the choledoc, as initially proposed (Table 2).

Considering there is not an padronized information on the papilla complacence, researchers of the clinical area suggest that the dilation should be done up to the diameter of $8 \mathrm{~mm}$, and use of lithotripsy when the stones are bigger, 
avoiding the papilla dilation beyond the normal caliber of the choledoc duct 3,9,12,13. The radiologic method used in this study proved itself to be adequate on the evaluation of effective papilla dilation, since it could be confirmed by the position of the dilation balloon in the inflation moment.

The manometry, for its evaluation of the contractile activity of the sphincter muscle, is considered an excellency method in the evaluation of the function of the major duodenal papilla ${ }^{16}$. This activity is translated as elevated basal pressure in the papilla region in relation to the choledoc duct and, more, as rhythmic contractile activity wit high pressure waves, here named contraction amplitude. The pressure in the choledoc duct can translate, although in an indirect way, the difficulty level in the emptying of the biliary ducts, and therefore it was also evaluated and compared in the two groups.

There is great difficulty when comparing the different literature studies concerning the pressure measures in the major duodenal papilla, because of the variation of parameters, such as the race and size of the animals, the kind of anaesthesic that was used, the papilla approaching method (transcystic or transduodenal), infusion speed and variables related to the machinery used. However, the measures of basal pressure of 19,9 $\mathrm{mmHg}$ and 17,3 mmHg, respectively in the group to be subjected to dilation and the control group, do not significantly differ from the averages found by Scott et al ${ }^{31}$ using the measure done through the duodenum, when it was observed pressures that varied between 13 and $22 \mathrm{mmHg}$. However, it is a bit bigger than what was observed by Takahata et $\mathrm{al}^{17}$, where it was foudn values around $13 \mathrm{mmHg}$, although they had performed evaluation through duodenostomy with Thomas cannula and infusion with flux of $0,2 \mathrm{ml} / \mathrm{min}$, smaller than the $0,3 \mathrm{ml} / \mathrm{min}$ used in this experiment.

The basal pressure is considered the best indicator of contractile activity of the major duodenal papilla, for it is the determinant factor of the pressure gradient between the choledoc duct and the duodenun and, therefore, the probable responsible for the reflux contention of the duodenal contents for the biliary ducts ${ }^{18,19}$. In the evaluation performed before the dilation or sham, the averages of the values of basal pressure, contraction amplitude and pressure in the choledoc duct did not show significant difference between the groups, determining a homgeinity of the sample (Table 3). The papilla dilation provoked a discreet reduction of the basal pressure immediately after the dilation. Though there is not statistic difference, it opposes the fear manifested in clinical work on the possibility that the dilation could produce difficulties in the bile emptying and cholestasis immediately after dilation ${ }^{20}$.

The present work is the first report in literature of the manometric evaluation performed immediately after the dilation in experimentation animal, and has practical interest on the possible cholestasis that would follow the postdilation days. The evaluations performed in the $7^{\text {th }}$ and $28^{\text {th }}$ days showed a progressive fall of the basal pressure in the animals subjected to dilation, being the difference a significant one in the $28^{\text {th }}$ day evaluation, when the average of the basal pressure was of $11,1 \mathrm{mmHg}$. The difference to the pressure before dilation represented a 44,2\% fall (Table
3). In the comparison between the groups, the basal pressure of the animals subjected to dilation was smaller than the basal pressure of the animals of the control group in the $28^{\text {th }}$ day evaluation, correlating, therefore, the dilation procedure with the reducing of the basal pressure of the papilla (Table 3). The only experimental work found on the sequential evaluation of the answer of the major duodenal papilla of dogs to dilation, the manometry was not performed straight after the dilation for the observation of the immediate response ${ }^{17}$. The successive evaluations showed a significant reduction of the basal pressure in the third day and a progressive fall, reaching $65 \%$ in 30 days, with partial recuperation in the 60 and 90 days evaluations ${ }^{17}$. The authors of the referred work suggest that the chronic inflammatory process noticed in the papuilla could be the cause of the persistent reduction of the basal pressure. However, the study of a sham group, in this work, found inflammatory process in the same incidence, with no significant reduction of the basal pressure.

This persistent reduction of the basal pressure was observed before in clinical works ${ }^{11,21}$, however they are questionable, since they have as initial evaluation patients with biliary ducts ailments.

Considering the influence of intervenient variables, the comparison with the control group was necessary to verify if the experimentation sham could also lead to alterations of basal pressure. It was verified a not significant fall of the basal pressure in the control group in the seven days evaluation and positive oscilation in the 28 days evaluation, against the persistent fall observed in the group with dilation (Table 3).

This reduction of basal pressure, in the control group, could be a consequence of the inihibition of the sphincter muscle of the choledoc, result of the inflammatory process found in the mucosa of nearly all animals. Although this inihibition reflex was not demonstrated in experimental studies, the apparent inihibition of the sphincter when stones were present in the choledoc ${ }^{22}$ could present similarity, suggesting the existence of an eventual choledochosphincter reflex ${ }^{23}$. However, it is necessary to reinstate that the reduction of the basal pressure was not significant. The amplitude of the contraction waves; other relevant motor manifestation of the sphincter muscle in the papilla; presented significant reduction in all phases after dilation, showing, as in the basal pressure case, the non recuperation of the contractile activity of the sphincter after dilation (Table 4). The result is in agreement with what was observer in the literature on what concerns the 28 days evaluation, but differs on what concerns the earlier evaluation, on which authors observed a discreet rise of the contraction amplitude ${ }^{17}$.

The animals in the sham group also had significant reduction of the contraction amplitude in the seventh day, but not in the twenty-eight day, indication a recuperation of this pressure after initial handling (Table 4). Such reduction, which occurred in the control group, determined that there would be significant difference between the groups in any moment of the evaluation, suggesting action of other factors in the inihibition of the cyclical contractile activity of the sphincter muscle. 
Considering that there is no avaiable work for the comparison of this observation of the control group, one can suppose a potential inihibtion potential of the inflammatory process of the papilla and of biliar contamination in the contractile activity of the sphincter muscle, as it was suggested for the basal pressure.

The pressure in the choledoc duct is bigger than the duodenal pressure due to the activity of the sphincter muscle, producing, therefore, a pressure gradient. After the dilation, there was an immediate elevation, not significant, of the choledoc duct pressure in the two groups of animals. Considering that there was not a corresponding rise of the basal pressure of contraction amplitude, this rise was possibly a result from a smaller gall bladder complacency. Negative pressure oscilation occurred in the seven days evaluation in both groups. However, in the 28 days evaluation, while the control group presented a recuperation of the initial pressure, the group of animals subjected to dilation presented a deeper negative pressure oscilation reaching statistical significance in relation with the initial pressure (Table 5). In the comparison between the groups, the difference was not significant, although this fact could seem to be consequence from casuistry, for the fall of the choledoc duct pressure had a similar behaviour to the basal pressure one. This result differs from what was observed in another study where there was not reduction of the pressure of the choledoc duct ${ }^{17}$.

There was great pressure variation in the manometry, probably due to the anatomic variations of the animals, which did not have a defined race. This fact broguht the need of a bigger number of animals and made the statistic analysis difficult. However, the observed alterations allowed conclusions that were compatible to the ones found in clinical and experimental studies ${ }^{11,17}$. The study in animals of a defined race could allow conclusions regarding the contraction amplitude and choledoc duct pressure, which seem to be more implied in the group with dilation, but with not significant difference in relation to the control group. Other limiting factor comes from the used procedure; the use of endoscopic dilation procedure could be a more faithful model without the situation of operatory trauma repeated in the seventh and twenty-eighth days. The search for alternatives that preserve the structure functions, such as the major duodenal papilla, is the symbol of the evolution of the medical practice. The animal experimentation allows the opportunity of investigation of new methods, antecipating complications and foreseeign results.

\section{Conclusion}

The function of the duodenal papilla is partially compromised with the dilation, since it provoked the reduction of basal pressue and compromising of the sphincter capacity in its cyclical contractions up until the 28 days of observation.

\section{References}

1. Kawai K, Akasaka Y, Murakami K, Tada M, Kohli Y, Nakajima M. Endoscopic sphincterotomy of the ampulla of Vater. Gastrointest Endosc. 1974; 20(4):148-51.

2. Madura JA; Madura JA; Sherman S; Lehman GA. Surgical sphincteroplasty in 446 patients. Arch Surg. 2005; 140(5):504-11.

3. Ochi Y, Mukawa K, Kiyosawa K, Akamatsu T. Comparing the treatment outcomes of endoscopic papillary dilation and endoscopic sphincterotomy for removal of bile duct stones. J Gastroenterol Hepatol. 1999; 14(1):90-6.

4. Bergman JJGHM, van Berkel A, Groen AK et al. Biliary manometry , bacterial characteristics , bile composition , and histologic changes fifteen to seventeen years after endoscopic sphincterotomy. Gastrointest Endosc. 1997; 45(5):400-5.

5. Cotton PB. Endoscopic retrograde cholangiopancreatography and laparoscopic colecystectomy. Am J Surg. 1993; 165:474-8.

6. Baillie J. Biliary sphincterotomy: less benign than once thought. Curr Gastroenterol Rep. 1999; 1(2):102-6.

7. Staritz M, Ewe K, Meyer zum Büschenfelde K-H. Endoscopic papillary dilatation, a possible alternative to endoscopic papillotomy. Lancet. 1982; 1:1306-7.

8. Mac Mathuna P, White P, Clarke E, Merriman R, Lennon JR, Crowe J. Endoscopic balloon sphincteroplasty (papillary dilation) for bile duct stones: efficacy, safety, and follow-up in 100 pacients. Gastrointest Endosc. 1995; 42(5):468-74.

9. Bergman JJGHM, Rauws EAJ, Fockens P et al. Randomized trial of endoscopic balloon dilation versus endoscopic-sphincterotomy for removal of bile duct stones. Lancet. 1997; 349:1124-9.

10. Natsui M, Narisawa R, Motoyama H et al. What is na appropriate indication for endoscopic papillary balloon dilation? Eur J Gastroenterol Hepatol. 2002; 14(6):635-40.

11. Yasuda I, Tomita E, Enya M, Kato T, Moriwaki H. Can endoscopic papillary balloon dilation really preserve sphincter of Oddi function? Gut 2001; 49(5):686-91.

12. Ohashi A, Tamada K, Tomiyama T et al. Epinephine irrigation for the prevention of pancreatic damage after endoscopic balloon sphincteroplasty. J Gastroenterol Hepatol. 2001; 16(5):568-71.

13. Komatsu Y, Kawabe T, Toda N et al. Endoscopic papillary balloon dilation for the management of common bile duct stones: experience of 226 cases. Endoscopy. 1998; 30 (1):12-7.

14. Boyden EA. The sphincter of Oddi in man and certain representative mammals. Surgery. 1937; 1:25-37.

15. Pappas TN, Powers M, Gottfried MR, Cotton PB. Balloon dilatation of the sphincter of Oddi facilitates passage of glass beads from the canine biliary tract. J Laparosc Surg. 1994; 4(6):413-7.

16. Coelho JCU, Wiederkehr JC - Motility of Oddi's sphincter: recent developments and clinical applications .Am J Surg. 1996; 172(1):48-51

17. Takahata S, Yokohata K, Nabae T et al. Sphincter of Oddi contractile function after balloon dilation: detailed manometric evaluation in conscious dogs. Gastrointest Endosc. 2000, 52(5):618-23.

18. Ohtsuka T; Yokohata K; Inoue K; Nabae T; Takahata S; Tanabe Y; Sugitani A; Tanaka M. Biliary sphincter motility after neural isolation of the pancreatoduodenal 
region in conscious dogs. Surgery. 2002; 131(2):139-48.

19. Nabae T; Takahata S; Konomi H; Deng ZL; Yokohata K; Chijiiwa K; Tanaka M. Effect of prepyloric gastric transection and anastomosis on sphincter of Oddi cyclic motility in conscious dogs. Gastroenterol. 2001; 36(8):530-7.

20. Tarnasky PR, Cunningham JT, Hawes RH, Hoffman BJ, Cotton PB. Pitfalls of bile duct stone removal after balloon sphincter dilation. Am J Gastroenterol. 1996; 91(4):822.

21. Sato H, Kodama T, Takaaki J, et al. Endoscopic papillary balloon dilatation may preserve sphincter of Oddi function after common bile duct stone management: evaluation from the viewpoint of endoscopic manometry. Gut. 1997; 41:541-4.
22. Matsumoto S; Tanaka M; Ikeda S; Yoshimoto H; Nakayama F. Sphincter of Oddi motor activity in patients with stones in gall-bladder, common bile duct or intrahepatic duct and the effect of morphine. J. Gastroenterol Hepatol. 1986; 1:213-20.

23. Shafik A. Choledochosphincter inhibitory reflex: identification of the reflex in dogs and its significance. $\mathrm{J}$ Surg Res. 1998; 78(1):7-10.

\section{Acknowledgments}

To the journalist Anna Carolina Negrini Fagundes for the present article's translation.

\section{Correspondence:}

Djalma José Fagundes

Rua Camé, 242/244, conjunto 33

03121-020 São Paulo - SP Brazil

Phone: (55 11)6604-4408

djfagundes.dcir@epm.br
Conflict of interest: none Financial source: none

Received: January 15, 2006 Review: February 22, 2006 Accepted: March 21, 2006

\section{How to cite this article:}

Zavadinack Netto M, Fagundes DJ, Bandeira COP. Manometric and radiographic evaluation of transduodenal sphincteroplasty (papillary dilation) in dogs. Acta Cir Bras. [serial on the Internet] 2006 July-Aug;21(4). Available from URL: http://www.scielo.br/acb

\section{Color figure available from www.scielo.br/acb}

